\title{
The Effects of Different Habitats and Morphological Variability on Cryptozona siamensis (Pfeiffer, 1856) in Chiang Mai Province
}

\author{
Thuangtong Boonmachai ${ }^{1}$ and Nattawadee Nantarat ${ }^{1,2,3,4^{*}}$
}

${ }^{1}$ Department of Biology, Faculty of Science, Chiang Mai University, Chiang Mai 50200, Thailand

${ }^{2}$ Applied Parasitology Research Laboratory, Department of Biology, Faculty of Science, Chiang Mai University 50200, Thailand

${ }^{3}$ Environmental Science Research Center, Faculty of Science, Chiang Mai University, Chiang Mai 50200, Thailand

${ }^{4}$ Science and Technology Research Institute, Chiang Mai University, Chiang Mai 50200, Thailand

*Corresponding author.E-mail: n_nantarat@yahoo.com https//:doi.org/10.12982/CMUJNS.2020.0053

Received: August 29, 2019 Revised: December 10, 2019 Accepted: February 13, 2020

\section{ABSTRACT}

Cryptozona siamensis is a species of snail found throughout Thailand which represents a potential plant pest. This snail has adapted to survive in various habitats, which might have impacted its genetics and shell morphology. To investigate this, we performed a detailed analysis of the snail and its habitat associations using DNA fingerprint analysis based on high annealing temperature randomly amplified polymorphic DNA (HAT-RAPD), cytochrome c oxidase subunit I (COI) markers, genitalia and geometric morphometric analysis of shell shape. A total of 240 C. siamensis individuals were collected from two different habitats: limestone mountains and lowland. Geometric morphometric analysis of $\mathrm{C}$. siamensis shell shape showed significant differences $(P<0.05)$ between the two habitat types. Moreover, HAT-RAPD, COI, and genitalia also showed significant differences. These results suggest that variation has occurred in C. siamensis snails from different habitats. This study may provide useful information for understanding the influence of ecology on genetic and morphological changes in some species of land snails.

Keywords: Cryptozona siamensis, Habitat, Phylogeny, Geometric, Morphometric 


\section{INTRODUCTION}

Land snails belonging to the phylum Mollusca, class Gastropoda, are a species-rich group with over 24,000 currently recognised species and over 35,000 species thought to be distributed worldwide(Lydeard and Cowie, 2004). Cryptozona siamensis (Pfeiffer 1856) is a land snail in the pulmonate group and Ariophantidae family. It is widely distributed throughout the Indochina region, including Thailand. Only one species of this genus has been reported in Thailand (Prasankok and Panha 2011). It usually lives on the ground, particularly in areas of decaying plant matter and on leaves or soft leaf tops, and is considered an antagonist for agriculture (Panha et al., 2011). Moreover, $C$. siamensis serves as the intermediate host for Angiostrongylus cantonensis (Vitta et al., 2016).

Cryptozona siamensis is found in great numbers in limestone karsts and lowland habitats throughout Thailand (Prasankok and Panha, 2011). Limestone karsts can form terrestrial habitat islands for calcium-dependent organisms, as they have alkaline soils and are rich in calcium (Schilthuizen et al., 2005). These factors can lead to an abundance of land snails that need calcium to produce their shells. Moreover, limestone has a fragmented distribution across large parts of Southeast Asia. Therefore, there is a high degree of endemism for certain snail taxa on individual hills (Clements et al., 2008). In contrast, lowland habitats are surrounded by a matrix of modified habitats, lowland rainforests and home gardens in villages. This area also has a lower calcium concentration than limestone karsts, along with low degrees of endemism (Schilthuizen et al., 2005).

Traditional classification of land snails is solely based on shell morphology, but this characteristic can vary due to environmental factors and other natural selective pressures. Morphometric analyses can provide information about the causal mechanisms underlying shape variation between gastropod populations (Vergara et al., 2017). Moreover, radular morphology is an important morphological criterion for taxonomic allocation. The radula is a specific characteristic feature of land snails which is important for feeding. It shows general similarities at the family and generic levels, but with consistent differences at the species level (Martín and Negretz, 2007; Jafar, 2015). These morphological characteristics can be used to identify species of some land snails that are difficult to differentiate.

Molecular taxonomic methods are useful tools to investigate and clarify the taxonomy of land snails. They are especially useful when identification based on morphological features fails. High annealing temperature randomly amplified polymorphic DNA (HAT-RAPD) is an inexpensive yet powerful typing method for many snail species because the high annealing temperature gives the great polymorphisms, reproducibility and resolution (Hebert et al., 2003; Butboonchoo and Wongsawad, 2017). The cytochrome c oxidase subunit 
I (COI) marker is another powerful tool for differentiating between closely related and morphologically indistinct species (Hebert et al., 2003; Desouky and Busais, 2012; Kulsantiwong et al., 2013; Nantarat et al., 2014).

This study will focus on two questions: (i) How do the Cryptozona siamensis of lowland rainforests and limestone karsts differ? and (ii) Can ecological variables explain significant variation in species composition independent of the effects of habitat type? We compared the morphological variation of $C$. siamensis snails from two different habitat types in Chiang Mai province based on their shells, genitalia and radular morphology, in addition to molecular analyses using HAT-RAPD and the COI gene marker.

\section{MATERIALS AND METHODS}

\section{Sampling and identification}

A total of 240 individuals of $C$. siamensis were collected from two different habitats including limestone mountains (Chiang Dao district, $\mathrm{n}=60$; and Mae On district, $\mathrm{n}=60$ ) and lowland (Mueang district, $\mathrm{n}=30$; Mae Taeng district, $\mathrm{n}=30$; Mae Rim district, $\mathrm{n}=30$; and San Kamphaeng district, $\mathrm{n}=30$ ) (Table 1, Figure 1). The snails were collected by picking them up by their shells directly by hand. Limestone karst is a geography formed from carbonate sedimentary rock, the main materials of which are calcite and aragonite minerals. There are different crystal forms of calcium carbonate $\left(\mathrm{CaCO}_{3}\right)$ which have underground drainage systems with sinkholes, caves (Schilthuizen et al., 2005; Clements et al., 2008) and intermediate forests. The intermediate forests are characterised by Excoecaria, Imbricaria and Deckenia plant genera. However, these intermediate forests are also home to various invasive exotic species. The elevation of limestone habitats in this study ranged from 504-512 $\mathrm{m}$ above sea level. Limestone karsts can form terrestrial habitat islands, leading to a high degree of endemism of land snails in this area (Schilthuizen et al., 2005). On the other hand, lowland is any broad expanse of land with a generally low elevation level, including lowland forests, ranging from 303-340 m above sea level. Lowland forest species like Imbricaria and Terminalia are known to dominate this area. The $\mathrm{pH}$, humidity and temperature are not significantly different $(P<0.05)$ between these two types of habitats. Details for the study area are shown in Table 1. 
Table 1. List of all localities recorded in Chiang Mai province.

\begin{tabular}{|c|c|c|c|c|c|c|}
\hline \multirow[t]{2}{*}{ Location } & \multicolumn{2}{|c|}{ Geographic coordinate } & \multirow{2}{*}{$\begin{array}{l}\text { Elevation } \\
(\mathrm{m}) \\
\text { above sea } \\
\quad \text { level }\end{array}$} & \multirow{2}{*}{$\begin{array}{c}\text { Temperature } \\
\left({ }^{\circ} \mathrm{C}\right)\end{array}$} & \multirow{2}{*}{$\begin{array}{l}\text { Humidity } \\
(\%)\end{array}$} & \multirow[t]{2}{*}{$\mathbf{p H}$} \\
\hline & Latitude $\left(\mathbf{N}^{\circ}\right)$ & $\begin{array}{c}\text { Longitude } \\
\left(\mathbf{E}^{\circ}\right)\end{array}$ & & & & \\
\hline $\begin{array}{l}\text { Chiang Dao } \\
\text { cave, Chiang } \\
\text { Dao district } \\
\text { (limestone } \\
\text { mountain) }\end{array}$ & $19^{\circ} 24^{\prime} 36^{\prime \prime}$ & $98^{\circ} 55^{\prime} 43^{\prime \prime}$ & 504 & 25.5 & 74 & 7.2 \\
\hline $\begin{array}{l}\text { Muang On cave, } \\
\text { Mae On district } \\
\text { (limestone } \\
\text { mountain) }\end{array}$ & $18^{\circ} 47^{\prime} 19^{\prime \prime}$ & $99^{\circ} 14^{\prime} 16^{\prime \prime}$ & 512 & 25.0 & 72 & 6.9 \\
\hline $\begin{array}{l}\text { Mueang Kaeo, } \\
\text { Mae Rim district } \\
\text { (lowland) }\end{array}$ & $18^{\circ} 54^{\prime} 33^{\prime \prime}$ & $98^{\circ} 58^{\prime} 35^{\prime \prime}$ & 303 & 25.5 & 76 & 7.5 \\
\hline $\begin{array}{l}\text { San Klang, San } \\
\text { Kamphaeng } \\
\text { district (lowland) }\end{array}$ & $18^{\circ} 39^{\prime} 44^{\prime \prime}$ & $98^{\circ} 52^{\prime} 18^{\prime \prime}$ & 303 & 26.0 & 68 & 6.9 \\
\hline $\begin{array}{l}\text { San Mahaphon, } \\
\text { Mae Taeng } \\
\text { district (lowland) }\end{array}$ & $19^{\circ} 07^{\prime} 49^{\prime \prime}$ & $98^{\circ} 56^{\prime} 57^{\prime \prime}$ & 340 & 28.0 & 68 & 7.6 \\
\hline $\begin{array}{l}\text { Suthep, Mueang } \\
\text { district (lowland) }\end{array}$ & $18^{\circ} 48^{\prime} 00^{\prime \prime}$ & $98^{\circ} 57^{\prime} 17^{\prime \prime}$ & 333 & 26.0 & 72 & 7.3 \\
\hline
\end{tabular}




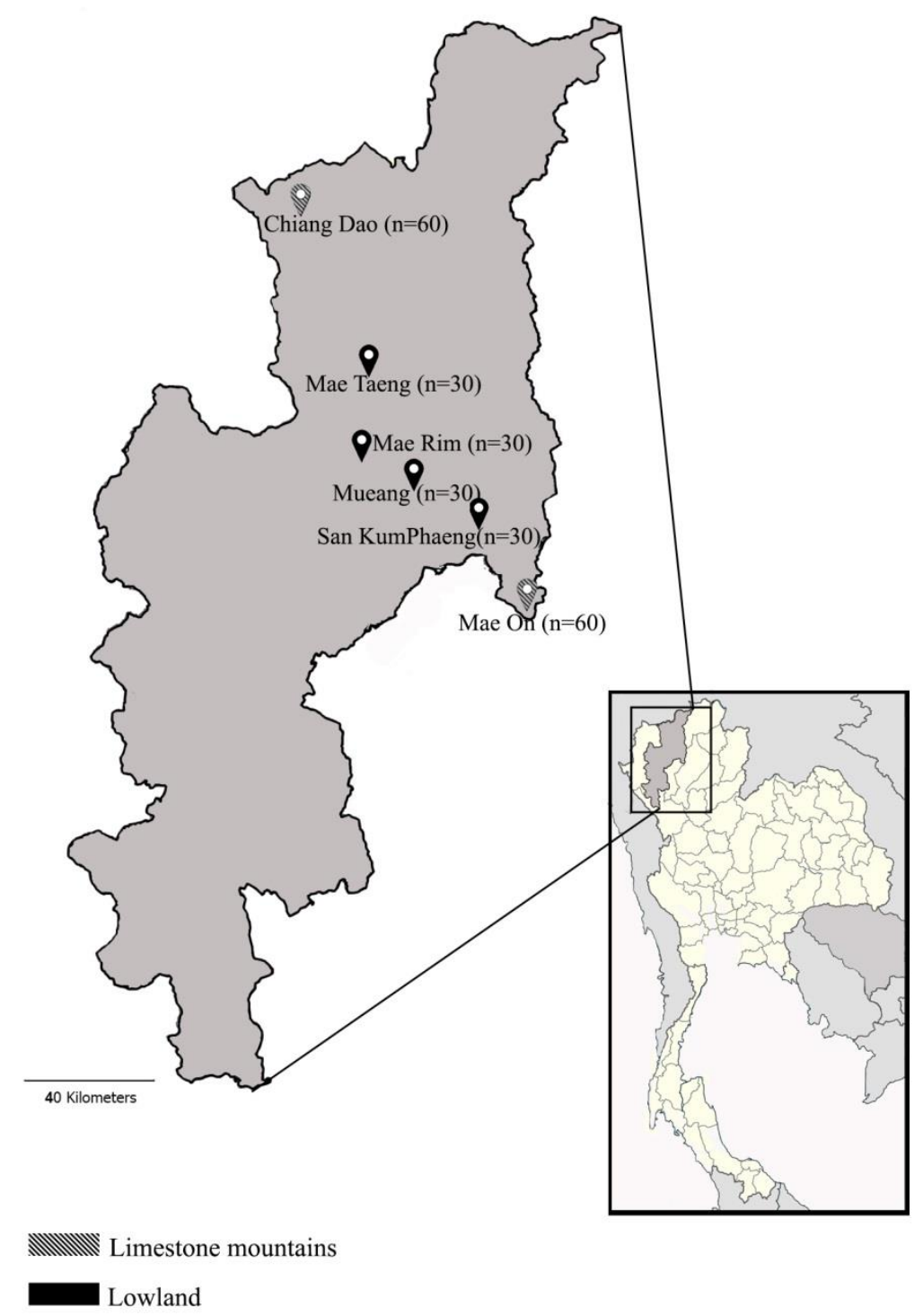

Figure 1. Sampling locations for specimens of Cryptozona siamensis in Chiang Mai province.

\section{Shell geometric morphometric analysis}

A total of 120 adult shells from each type of habitat (limestone karsts and lowland) were studied for geometric morphometric analysis. Each shell specimen was attached to a stage, then pictures were taken with a tripodmounted Nikon 5300 digital camera, followed by landmark digitisation. The shells were orientated in such a way to ensure the same view of their position (Francoy et al., 2012; Gladstone et al., 2019). The photos were randomly ordered in tpsUtil v.32 (Rohlf, 2012), followed by digitisation of landmarks and outlines for geometric morphometric analyses. This process defines nine landmarks on bidimensional coordinates (Francoy et al., 2012; Nantarat et al., 
2014; Gladstone et al., 2019) using tpsDig2 v.2.32 (Rohlf, 2010), shown in Figure 3A. Geometric morphometric analyses were performed using the software package MORPHOJ v1.05c (Klingenberg, 2011). Shell shape variation was identified using principal component analysis (PCA) and canonical variance analysis (CVA) (Nantarat et al., 2014).

\section{Study of genitalia and radular morphology}

Living specimens were photographed, stored at $-20^{\circ} \mathrm{C}$, then preserved in $70 \%$ ethanol (v/v) for anatomical studies. Identifications were based on Pfeiffer (1856) and Prasankok and Panha (2011). Groups of 10 adult snails from each habitat were randomly selected. The snails were dissected to study the reproductive system. Genitalia were examined and digital images were taken using Cell'D imaging software. All specimens from each habitat were dissected and the genitalia examined under a stereomicroscope, and representative specimens were selected for illustration under a camera lucida.

Radular were extracted from the buccal mass under a stereomicroscope, boiled in $10 \%$ sodium hydroxide solution for about $5 \mathrm{~min}$, then washed in distilled water. Dehydration was performed by immersing the radula in increasing concentrations of alcohol $(10 \%, 20 \%, 30 \%, 50 \%, 70 \%$ then $85 \%)$, then specimens were stained with 5\% eosin, placed into 95\% xylol and mounted on a slide (Sutcharit et al. 2018). These permanent slides were subsequently examined under a light microscope to assess patterns of the central tooth, lateral teeth and marginal teeth of the radula (Seed, 2015).

Anatomical abbreviations. ag, albumen gland; at, atrium; fo, free oviduct; gd, gametolytic duct; gs, gametolytic sac; hd, hermaphroditic duct; ov, oviduct; p, penis; pr, penial retractor muscle; ps, penial sheath; psr, penial sheath retractor muscle; sv, seminal vesicle; ta, talon; v, vagina; vc, vaginal caecum; vd, vas deferens (Inkhavilay et al., 2016).

\section{High annealing temperature randomly amplified polymorphic DNA (HAT- RAPD) analysis}

Total DNA was extracted from foot tissue of 35 individuals from each locality. Then, samples were incubated at $55^{\circ} \mathrm{C}$ for $1 \mathrm{~h}$ then $95^{\circ} \mathrm{C}$ for $30 \mathrm{~min}$ with $150 \mu \mathrm{l}$ of Chelex ${ }^{\circledR} 100$ and $3 \mu \mathrm{l}$ of proteinase $\mathrm{K}$ (Walsh, Metzger, and Higuchi, 2013). All DNA samples were stored at $-20^{\circ} \mathrm{C}$.

Amplification was performed using commercially available arbitrary 10-mer primers (Operon Biotechnology, Huntsville, Alabama, USA). Fifteen primers were used to screen the samples but only eight primers produced clearly reproducible bands, so these were selected for HAT-RAPD. These primers included OPA02, OPA03, OPA04, OPA10, OPN02, OPN03, OPN04 and OPN06. The HAT-RAPD reaction was carried out in a $20-\mu 1$ reaction mixture containing $2 \mu \mathrm{l}$ of $1 \times$ PCR buffer, $0.8 \mu \mathrm{l}$ of $\mathrm{MgCl}_{2}, 0.4 \mu \mathrm{l}$ of dNTP, $1 \mu \mathrm{l}$ of each primer, $0.3 \mu \mathrm{l}$ of $\mathrm{Taq}$ DNA polymerase, $14 \mu \mathrm{l}$ of deionised $\mathrm{H}_{2} \mathrm{O}$ and $1.5 \mu \mathrm{l}$ of 
DNA template. PCR protocols were as follows: one cycle of $94^{\circ} \mathrm{C}$ for $2 \mathrm{~min} ; 40$ cycles of $94^{\circ} \mathrm{C}$ for $30 \mathrm{~s}, 45^{\circ} \mathrm{C}$ for $1.30 \mathrm{~min}, 72^{\circ} \mathrm{C}$ for $45 \mathrm{~s}$; and one cycle of final extension at $72^{\circ} \mathrm{C}$ for $7 \mathrm{~min}$. HAT-RAPD PCR products were separated by $1 \%$ TBE agarose gel electrophoresis mixed with RedSafe nucleic acid staining solution, electrophoresed in $0.5 \times \mathrm{TBE}$ buffer at $100 \mathrm{~V}$ for $45 \mathrm{~min}$. The bands were visualised under UV light (Sripalwit et al., 2007; Wongsawad, 2010).

HAT-RAPD fragments were selected according to two criteria: (1) they showed polymorphism among the different stocks, and (2) the polymorphisms were constant and reproducible among individuals and bulked samples of the same line. At the onset of this analysis, samples were bulked to establish whether major genetic markers identified in the individual snails would be reproducibly amplified for pooled samples. In addition, bulking the samples was used to determine whether this method would be able to reduce the sample size without affecting the assay. Each sample was scored as either present (1) or absent (0), then transformed into the character matrix in the text document program. A dendrogram was constructed based on the genetic distance matrix using Phylip software V.3.695 (Tuimala, 2004). Phylogenetic trees were reconstructed using neighbour joining $(\mathrm{NJ})$ method.

\section{Phylogenetic analysis}

The taxonomic sampling scheme used herein included four representative Cryptozona siamensis samples from two different habitat types and two outgroup species (Macrochlamys sp. from Genbank MF983633-M983634). Genomic DNA from snail foot tissue was prepared as above. The mitochondrial cytochrome oxidase subunit I (COI) gene were amplified using primers : LCOI490 (5'-GGTCAACAAATCATAAAGATATTGG-3') and HCO2198 (5'-TAAACTTCAGGGTGACCAAAAAATCA-3') (Folmer et al., 1994). PCR was performed in $20 \mu \mathrm{l}$ reactions with $25 \mu \mathrm{l} 2 \mathrm{x}$ Illustra Hot Start Master Mix (GE Healthcare), $10 \mathrm{M}$ each primer, deionized water and approximately $10 \mathrm{ng}$ DNA template. Thermal cycling condition was: $94^{\circ} \mathrm{C}$ for $2 \mathrm{~min}, 36$ cycles of $94^{\circ} \mathrm{C}$ for $30 \mathrm{~s}, 42^{\circ} \mathrm{C}$ for $2 \mathrm{~min}$ and $72^{\circ} \mathrm{C}$ for $2 \mathrm{~min}$, and a final extension step of $72^{\circ} \mathrm{C}$ for $5 \mathrm{~min}$. The amplified products were checked with $1 \%(\mathrm{w} / \mathrm{v})$ agarose gel electrophoresis using $1 \mathrm{X}$ TBE buffer. Gels were run at $100 \mathrm{~V}$ for $45 \mathrm{~min}$ and visualized with RedSafe nucleic acid staining solution and UV transillumination. PCR products were purified and sequenced using BigDye ${ }^{\circledR}$ Terminator v3.1 cycle sequencing kit chemistry and 1st BASE DNA Sequencing Services (Applied Biosystems).

The sequences were visually checked and edited as necessary with ClustalW (Thompson et al., 1994), as implemented in MEGA X (Kumar et al., 2018). COI was translated to check the amino acid sequence, stop codons and frameshift mutations. All newly generated sequences have been deposited in GenBank. Phylogenetic trees were reconstructed using neighbour joining (NJ) 
and maximum likelihood (ML). jModeltest 0.1.1 (Darriba et al., 2012) was used to evaluate the best evolutionary substitution model under Akaike's information criterion (AIC) (Akaike, 1974). The NJ analysis was performed using PAUP* v4.0 (Swofford, 2003) based on appropriate models $(\mathrm{GTR}+\mathrm{G})$. One thousand replicates of bootstrap resampling (Felsenstein, 2008) were performed to assign support to branches in the NJ tree. ML was performed using PhyML v.3 (Criscuolo, 2011), with 1,000 bootstrap replicates (Felsenstein, 2008; Felsenstein, 2010).

\section{RESULTS}

\section{Morphological analysis}

Shell. The shell of $C$. siamensis is depressed and has 6-8 whorls. The shell is dextral type. The upper side is a pale rust-red colour, the underside is entirely pale yellow to white, and the aperture is roundly lunate. In this study, morphological examination of $C$. siamensis specimens from limestone mountain and lowland habitats showed similar shell characteristics (Figure 2A, E).

Radula. Cryptozona siamensis from both habitats were examined under a light microscope. The radula morphology of all $C$. siamensis was polyglossan type with the general formula $\infty: \infty: 1: \infty: \infty$. Each row of radular teeth consisted of one central tooth and numerous lateral and marginal teeth. The radular teeth of $C$. siamensis collected from the limestone mountain and lowland habitats were similar in the number of radular teeth, consisting of one central tooth, 20 lateral teeth and 62 marginal teeth (Figure 2B, F).

Genital organs. Cryptozona siamensis specimens from lowland and limestone mountain habitats showed a similar reproductive system. Atrium (at) is short. Penis is prolonged, slightly enlarged and cylindrical in shape. Distally cylindrical is corresponding to penial verge. Penial caecum (pc) is slightly prolonged. Epiphallus (e) is a slender tube, separated by two bulbs that are connected at the end, with a black branch attached with a flagellum. Flagellum (fl) is large, irregular and coiled. Vas deference (vd) is a slim tube connected between the distal end of the epiphallus and oviduct. Vagina (v) is long and cylindrical. Dart apparatus (da) is long, cylindrical and curved like a hook, located at the proximal end of the vagina. Gametolytic sac (gs) is elongated and bulbous. Gametolytic duct (gd) is long and cylindrical. Oviduct (ov) has large lobules with a prostate gland (pg) that lies alongside.

Snails from the two habitats showed some variance in their reproductive systems. The length of the penis (p) was on average $0.56 \pm 0.11 \mathrm{~cm}$. in snails collected from lowland and $0.96 \pm 0.13 \mathrm{~cm}$ in those from limestone mountain habitats and significant difference at $P<0.05$. In addition, the oviduct (ov) of snails from lowland habitats showed larger lobules, while the vagina (v) of snails from lowland $(0.59 \pm 0.10 \mathrm{~cm}$.) was shorter (significant difference at $P<0.05)$ and more cylindrical when compared to those from limestone mountains $(0.77 \pm 0.21 \mathrm{~cm}$.) (Figures $2 \mathrm{C}-\mathrm{D}$ and $\mathrm{G}-\mathrm{H})$. 


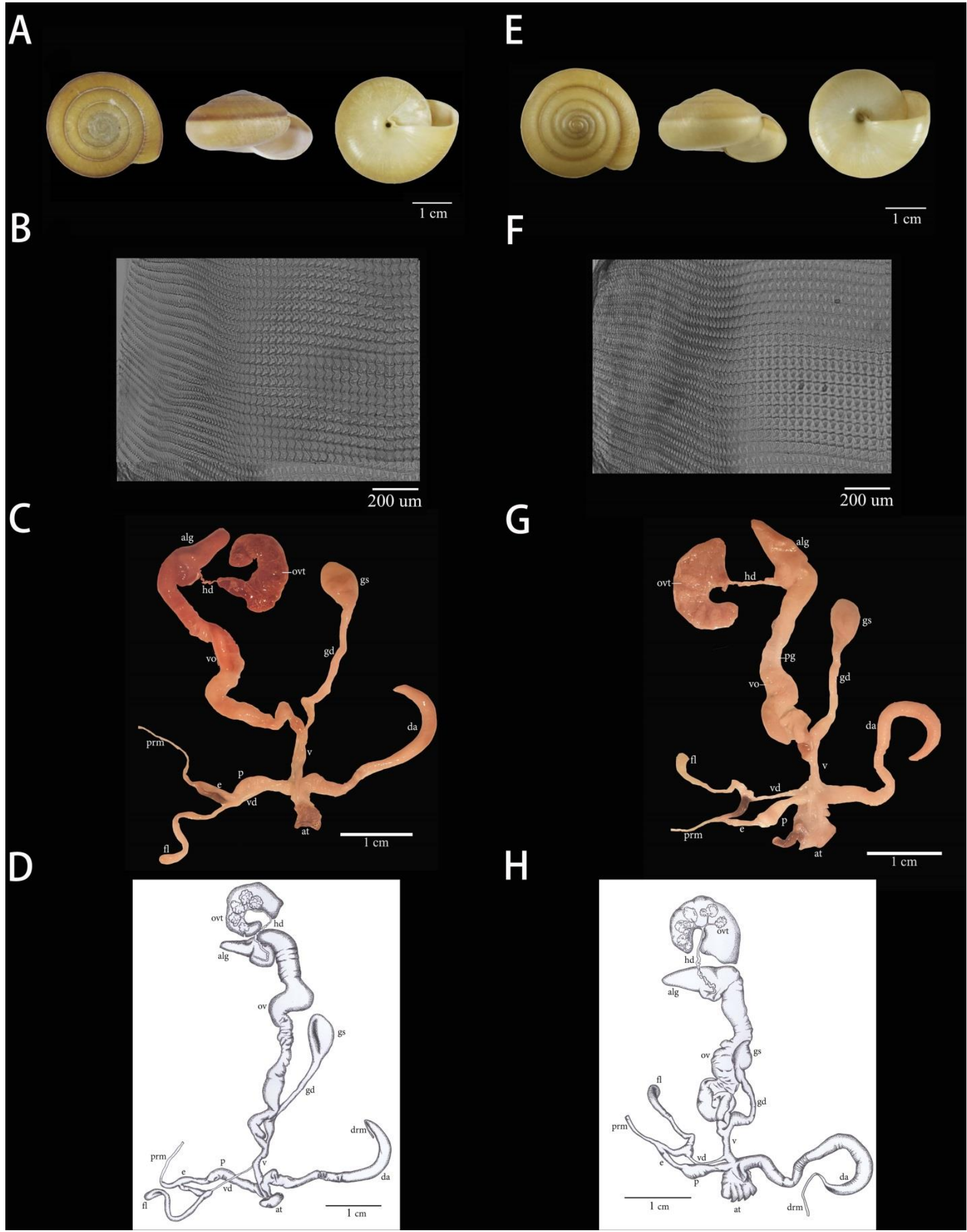

Figure 2. Morphology of Cryptozona siamensis from (A-D) limestone mountain and $(\mathrm{E}-\mathrm{H})$ lowland habitats: $\mathrm{A}, \mathrm{E})$ shell; $\mathrm{B}, \mathrm{F})$ radula; $\mathrm{C}-\mathrm{D}$ and $\mathrm{G}-\mathrm{H})$ genitalia. 


\section{Geometric morphometric analyses}

Principal component analysis Radula. Cryptozona siamensis from both habitats were examined under a light microscope. The radula morphology of all C. siamensis was polyglossan type with the general formula $\infty: \infty: 1: \infty: \infty$. Each row of radular teeth consisted of one central tooth and numerous lateral and marginal teeth. The radular teeth of $\mathrm{C}$. siamensis collected from the limestone mountain and lowland habitats were similar in the number of radular teeth, consisting of one central tooth, 20 lateral teeth and 62 marginal teeth (Figure 2B, F). of $C$. siamensis from limestone mountain and lowland habitats generated a graphic that displays shape differences by the relationship between the two principal components (PCs) obtained (Figure 3B). The PCs accounted for $44.292 \%$ of the total variance. The first principal component axis (PC1) explained $23.045 \%$ of the shape variability, while the second principal component axis (PC2) accounted for $21.247 \%$.

The variation among groups, scaled for the inverse within-group variation of canonical variate analysis (CVA), explained 0.185 of eigenvalues of the shape variability. Overall, individuals from both clades were clustered with a large amount of overlap. However, when testing for differences between clades, the results showed significant differences based on permutation tests, with a Mahalanobis distance of $0.856(P<0.0001)$ and Procrustes distance of 0.012 $(P<0.0008$; Figure 3C). The shell shapes from both habitats were significantly different with regard to aperture and body whorl (Figure 3). The last whorl of the snails from the limestone mountain habitat was larger and more oblique than those from the lowland (Figure 3C). 
(A)

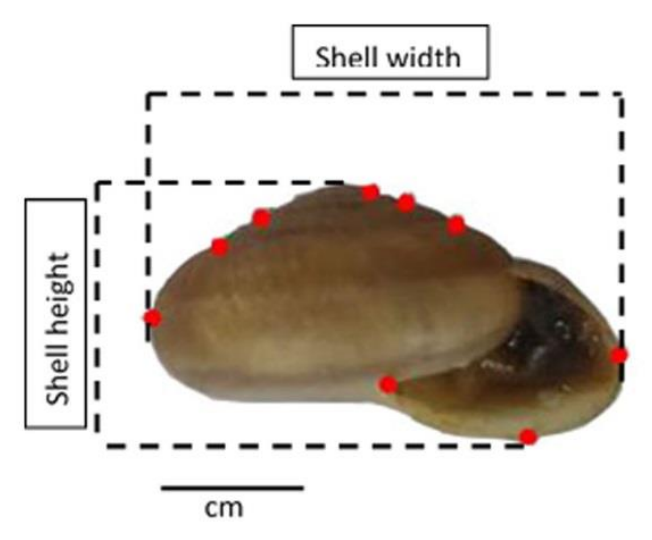

(C)

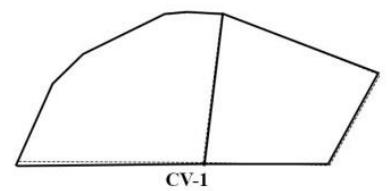

(B)

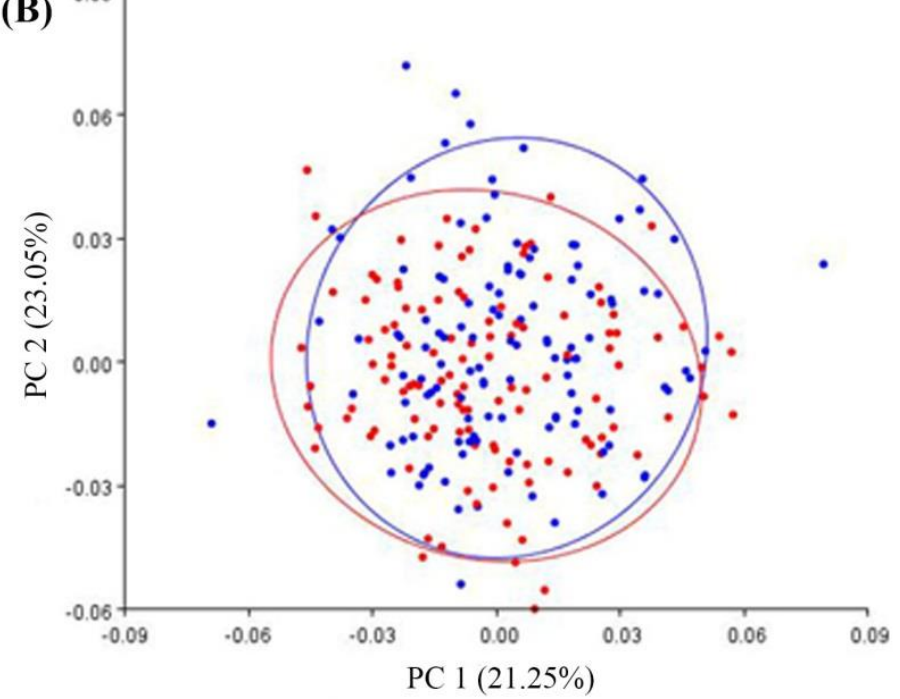

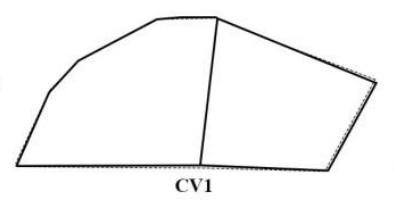
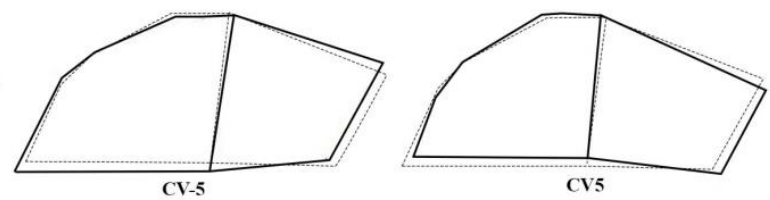

Figure 3. Geometric-morphometric study of shell shape variation of Cryptozona siamensis. (A) Shell photo showing the measurements and landmarks (red spot) used in this study. (B) Plots of individual scores for the two canonical variates (CVs) derived from canonical variate analysis (CVA). Blue plots represent individuals of $C$. siamensis collected from the limestone mountain habitat, while red plots represent those from the lowland habitat. (C) Wireframes showing the shape deformations (solid line) from the consensus configuration (dotted line) to each extreme negative and positive $\mathrm{CV}$. Shape changes along CV1 are shown on the left and CV5 on the right.

\section{Molecular analysis}

A phylogenetic tree of $C$. siamensis from the two different habitats and relative groups was reconstructed using HAT-RAPD with eight primers and COI markers. The DNA profiles of land snails from the two different habitats presented different banding patterns (supplementary 1).

The results of the NJ phylogenetic tree (HAT-RAPD; Figure 4A) and ML phylogenetic tree (COI; Figure 4B) showed similar topologies. The trees consisted of two major clades: clade A, all C. siamensis; and clade B, outgroup (Sarika sp.). Clade A was separated into two subclades: clade 1A, C. siamensis from limestone mountains (Chiang Dao district and Mae On district); and clade 2A, C. siamensis from lowland (Mueang district and San Kamphaeng district). 
Clade A, all C. siamensis and clade B, outgroup (Macrochlamys sp.). Clade A was separated into two subclades: clade $1 \mathrm{~A}, C$. siamensis from limestone mountains (Chiang Dao district and Mae On district); and clade 2A, C. siamensis from lowland (Mueang district and San Kamphaeng district). There was moderate high bootstrap supports for the ML tree (COI; Figure 4B). The $\mathrm{K} 2 \mathrm{P}$ distance between COI genes of specimens from lowland and limestone mountains was $2 \%$ (within group 0.00150-0.00153) but when compared with outgroup, the K2P distance ranged from 13-14\%.
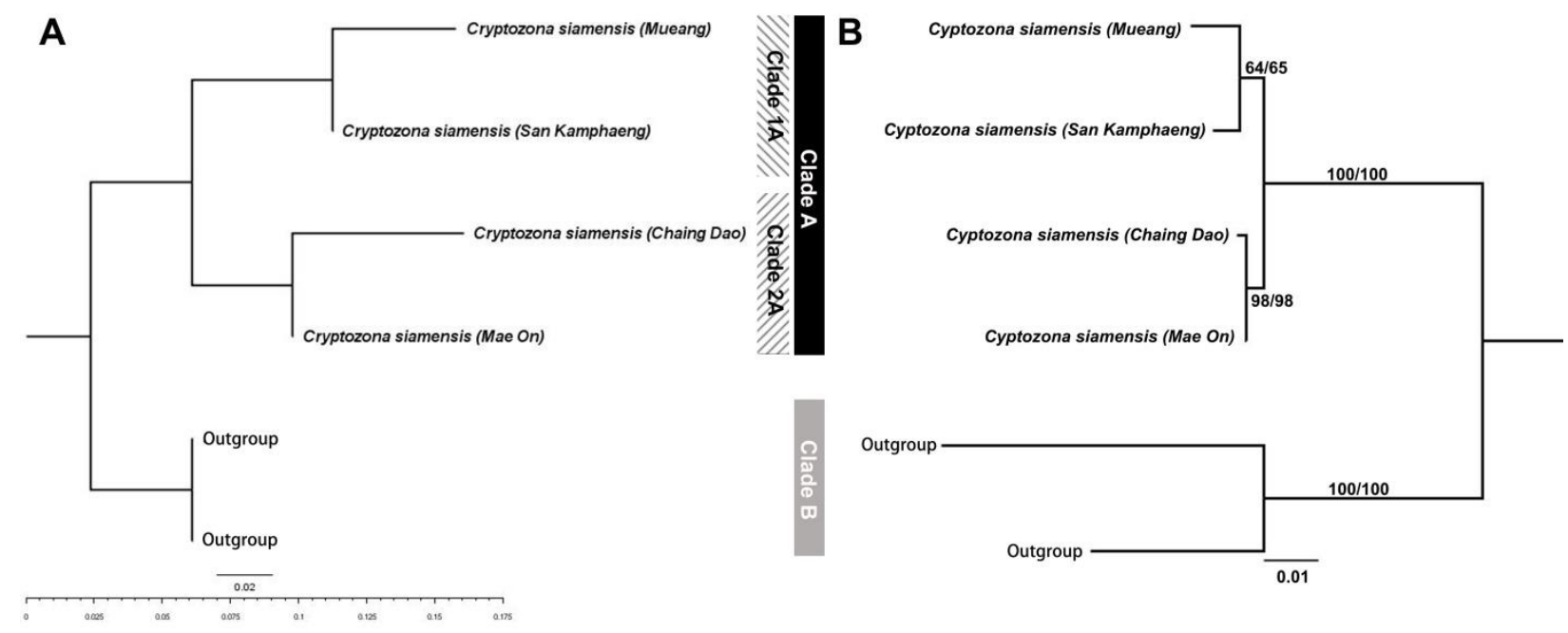

Figure 4. Phylogenetic trees of Cryptozona siamensis from two different habitats, with Macrochlamys sp. as an outgroup. (A) Tree reconstructed using the neighbor joining method based on HATRAPD with eight primers. B) Tree reconstructed using the maximum likelihood method based on the COI gene $(659 \mathrm{bp}$.). Bootstraps of $\mathrm{NJ}$ and ML methods are provided at the nodes, respectively.

\section{DISCUSSION}

We examined differences in the morphology of Cryptozona siamensis snails collected from limestone mountains and lowland of Chiang Mai province, Thailand. The results for shell morphology show significant differences between snails from the limestone mountains and lowland of Chiang Mai province, which is supported by geometric morphometric methods $(P<0.05)$. Habitats are one of the most important factors that influence morphological variation of animal species (Schilthuizen et al., 2005). Moreover, the mineral compounds present in soils in limestone mountains and lowland are different. In particular, the limestone mountains contain a larger amount of calcium than the lowland (Schilthuizen et al., 2005). Land snails living on calcareous substrates 
sometimes have thicker shells, as well as some differences in shell morphology (Goodfriend, 1986).

Radular characteristics are also used in systematic molluscan studies. The taxonomic usefulness of radula characteristics has been questioned, as similar characteristics may be the result of homoplasy. However, the radula is one of the structures used to investigate the effects of environmental heterogeneity on natural populations and potential phenotypic plasticity (Medina et al, 2016). We used scanning electron microscopy (SEM) to perform a detailed investigation of the radula morphology (Nantarat et al., 2014; Chomchoei et al., 2018). The results showed that $C$. siamensis from both habitats were polyglossan type, with a general formula of $\infty: \infty: 1: \infty: \infty$. However, the radular teeth of $C$. siamensis snails from the limestone mountain and lowland were similar in number, consisting of one central tooth, 20 lateral teeth and 62 marginal teeth (Figure 2A and B).

Genital morphology, which is less dependent on the environment, has been utilised for specific taxonomy (Inkhavilay et al. 2016). However, the genital system of $C$. siamensis from the two habitats showed high similarity except for a few notable differences. The length of the penis (p) differed, with an average of $0.85 \mathrm{~cm}$ in snails from the lowland and $0.66 \mathrm{~cm}$ in those from limestone mountains. The shape of the oviduct (ov) of snails from lowland showed larger lobules when compared with those from limestone mountains, while the vagina (v) of snails from lowland were shorter and more cylindrical (average $0.54 \mathrm{~cm}$ in lowland snails and $0.70 \mathrm{~cm}$ in limestone mountain snails). Character displacement is also implicated in genital diversification and coevolution of penis and vagina length in land snails (Kameda et al., 2009). In allopatry, species diverge and come into subordinate contact, then natural selection against interspecific mating can cause character divergence that promotes mating discrimination. This process accomplishes full reproductive isolation between populations or species with incomplete postzygotic isolation (Kameda et al. 2009). This process might also favour character divergence to facilitate partner discrimination and avoid mating interference. This is important evidence supporting the differences observed in $C$. siamensis, and also signals that speciation may occur in the near future.

The dependence on morphological characteristics, such as the shell, may possible causes by phenotypic plasticity and locations (Kulsantiwong et al., 2013). Therefore, molecular phylogenetic methods are often used to simplify differentiation of species with similar characteristics, thereby eliminating previous variation problems (Nantarat et al., 2014). HAT-RAPD analysis and phylogeny based on the COI gene of $C$. siamensis revealed remarkable variation between the two habitat types (limestone mountains of the Chiang Dao and Mae On districts, and lowland of the Mueang and San Kamphaeng districts; Figure 1). Accordingly, these results suggest that their similarity and differences from populations located in the middle lowland cannot be explained by isolation by 
distance. Nevertheless, the genetic similarity among populations in the lowland could simply be explained by gene flow occurring within shared areas (Prasankok and Panha, 2011). Consequently, it emphasises the discovery of unexpected genetic similarities between the most distant populations (limestone mountain, Figure 1). Compared to other pulmonate snails, C. siamensis generally shows similar values of genetic variability (Prasankok and Panha, 2011). Factors such as bionomic features, a large population size, ecological factors and a wide niche throughout its geographic distribution can drive the high degree of genetic variability observed within snail species (Chiba, 2010; Prasankok and Panha, 2011). Cryptozona siamensis is considered to have a large population size due to its abundance, high density and wide geographic range (Pfeiffer, 1856; Prasankok and Panha, 2011). In this study, we found significant differences between $C$. siamensis from different habitat types, supported by differences in morphological characteristics including the shell, genitalia and phylogeny.

\section{CONCLUSION}

Morphological and molecular analyses were performed on Cryptozona siamensis from Chiang Mai province, Thailand. We found differences in C. siamensis from the two habitat types, which could be caused by phenotypic plasticity. Moreover, the influence of environmental factors is also important, contributing to adaptations of $C$. siamensis. HAT-RAPD profiling and the COI gene were found to be useful tools to assess the genetic relationship between land snail species. Moreover, we probably identified character displacement in C. siamensis, evidenced by differences in penis and vagina length. This is a sign that speciation may occur in this land snail. Thus, geographic pattern analysis of morphological variation in land snail genitalia provides a promising new way to understand the general mechanisms of prezygotic isolation. Future research into the phylogeny and genitalia of this snail across their entire distribution range may help to understand and confirm these findings. This study will help to better understand the taxonomic approach for $C$. siamensis and develop methods for the management and control of this land snail in the future.

\section{ACKNOWLEDGEMEMTS}

This study was partially supported by Chiang Mai University. Grateful thanks are extended to Parasitology Research Laboratory for available instruments. Thanks to the supply for a graduate student (TB) through The Royal Golden Jubilee Ph.D. Program (PHD/0248/2560). 


\section{REFERENCES}

Akaike, H. 1974. A new look at the statistical model identification. IEEE Transactions on Automatic Control. 19(6): 716-723. https://doi.org/10.1109/TAC.1974.1100 705

Butboonchoo, P., and Wongsawad, C. 2017. Occurrence and HAT-RAPD analysis of gastrointestinal helminths in domestic chickens (Gallus gallus domesticus) in Phayao province, Northern Thailand. Saudi Journal of Biological Sciences. 24(1): 30-35. https://doi.org/10.1016/j.sjbs. 2015.09.002

Chiba, S. 2010. Species diversity and conservation of Mandarina, an endemic land snail of the Ogasawara Islands. Restoring Ocean Isl Ecosyst Impact Manag Invasive Alien Species Bonin Islands. 117-125. https://doi.org/ 10.1007/978-4-431-53859-2_18

Chomchoei, N., Wongsawad, C., and Nantarat, N. 2018. Investigation of cryptic diversity and occurrence of echinostome metacercariae infection in Anentome helena (von dem Busch, 1847). Asian Pacific Journal of Tropical Medicine. 11(10):590-596. https://doi.org/10.4103/1 995-7645.244524

Clements, G.R., Lu, X.X., Ambu, S., Schilthuizen, M., and Bradshaw, C. 2008. Using biogeographical patterns of endemic land snails to improve conservation planning for limestone karsts. Biological Conservation. 141: 2751-2764. https://doi.org/10.1016/j.biocon.2008.08.011

Criscuolo, A. 2011. Molecular phylogenetics and evolution morePhyML: improving the phylogenetic tree space exploration with PhyML 3. Molecular Phylogenetics and Evolution. 61(3): 944-948. https://doi.org/ 10.1016/j.ympev.2001.08.029

Darriba, D., Taboada, G.L., Doallo, R., and Posada, D. 2012. jModelTest 2: more models, new heuristics and parallel computing. Nature Methods. 9(8): 772. https://doi.org/10.1038/nmeth.2109

Desouky, M.M.A., and Busais, S. 2012. Phylogenetic relationships of the land snail; Eobania vermiculata (Müller, 1774) from Egypt and Saudi Arabia. A combined morphological and molecular analysis. The Journal of Basic and Applied Zoology. 65(2): 144-151. https://doi.org/10.1016/J.JOBAZ.2012.07.009. [accessed 2019 Jan16]. https://www.sciencedirect. com/science/article/pii/S209098 9612000276.

Felsenstein, J. 2008. Bootstraps and testing trees. Presentation. 71(2). Available from https://publication/uuid/FF574B71-EBF4-44B39C94E3D6AC19ED83.

Felsenstein, J. 2010. Confidence limits on phylogenies: an approach using the bootstrap. Evolution (N Y). 39(4): 783-791. https://doi.org/10.2307/240 8678. http://www.jstor.org/stable/2408678. 
Folmer,O., Black, M., Hoeh, W., Lutz, R., and Vrijenhoek, R. 1994. DNA primers for amplification of mitochondrial cytochrome $\mathrm{c}$ oxidase subunit I from diverse metazoan invertebrates. Molecular Marine Biology and Biotechnology. 3(5): 294-299. https://www.scopus.com/inward/record. uri?eid=2-s2.00028528103\&partnerID $=40 \& \mathrm{md} 5=8 \mathrm{c} 364 \mathrm{e} 37 \mathrm{a} 9072 \mathrm{ebb} 20$ 209d170a3cfe06.

Francoy, T., Franco, F.F, Roubik, D., Francoy, T.M., De Faria Franco, F., and Roubik, D.W. 2012. Integrated landmark and outline-based morphometric methods efficiently distinguish species of Euglossa (Hymenoptera, Apidae, Euglossini). Apidologie. 43(6). https://doi.org/10.1007/s13592-012-0132-2ï.

Gladstone, N.S., Niemiller, M.L., Pieper, E.B., Dooley, K.E., and McKinney, M.L. 2019. Morphometrics and phylogeography of the caveobligate land snail Helicodiscus barri (Gastropoda, Stylommatophora, Helicodiscidae). Subterranean Biology. 30: 1-32. https://doi.org/10.3897/ subtbiol.30.35321

Goodfriend, G.A. 1986. Variation in land-snail shell form and size and its causes: a review. Systematic Zoology. 35(2): 204. https://doi.org/10.2307/ 2413431

Hebert, P.D.N., Ratnasingham, S., and deWaard, J.R. 2003. Barcoding animal life: cytochrome c oxidase subunit 1 divergences among closely related species. Proceedings of the Royal Society B Biological Sciences. 270(Suppl

1):S96-S99.

http://www.ncbi.nlm.nih.gov/pmc/articles/PMC1698023/. https://doi.org/10.1098/rsbl.2003.0025

Inkhavilay, K., Siriboon, T., Sutcharit, C., Rowson, B., and Panha, S. 2016. The first revision of the carnivorous land snail family Streptaxidae in Laos, with description of three new species (Pulmonata, Stylommatophora, Streptaxidae). Zookeys. 2016(589): 23-53.https://doi.org/10.3897/ zookeys.589.7933.

Kameda, Y., Kawakita, A., and Kato, M. 2009. Reproductive character displacement in genital morphology in satsuma land snails. The American Naturalist. 173(5): 689-697. https://doi.org/10.1086/597607.

Klingenberg, C.P. 2011. MorphoJ: an integrated software package for geometric morphometrics. Molecular Ecology Resources. 11(2): 353-357. https://doi.org/10.1111/j.1755-0998.2010.02924.x.

Kulsantiwong, J., Prasopdee, S., Piratae, S., Khampoosa, P., Suwannatrai, A., Duangprompo, W., Boonmars, T., Ruangjirachuporn, W., Ruangsittichai, J., and Viyanant, V., et al. 2013. Species-specific primers designed from RAPD products for Bithynia funiculata, the first intermediate host of liver fluke, Opisthorchis viverrini, in North Thailand. The Journal of Parasitology. 99(3): 433-437. https://doi.org/10. 1645/ge-3138.1 
Kulsantiwong, J., Prasopdee, S., Ruangsittichai, J., Ruangjirachuporn, W., Boonmars, T., Viyanant, V., Pierossi, P., Hebert, P.D.N., and Tesana, S. 2013. DNA barcode identification of freshwater snails in the family bithyniidae from Thailand. PLoS One. 8(11): 1-9. https://doi.org/10.137 1/journal.pone.0079144

Kumar, S. , Stecher, G., and Tamura, K. 2018. MEGA7 : molecular evolutionary genetics analysis version 7.0 for Bigger Datasets. Molecular Biology and Evolution.33(7):1870-74. https://doi.org/10.1093/molbev/msw054

Lydeard, C., and Cowie, R.H. 2004. The global decline of nonmarine mollusks a pan-european species-directories infrastructure (PESI) view project taxonomy of NA unionidae view project. Bioscience. 54(4): 321-330. https://doi.org/10.1641/0006-3568(2004)054[0321:TGDONM]2.0.CO;2.

Martín, S., and Negrete, L. 2007. Radular ultrastructure of South American Ampullariidae (Gastropoda: Prosobranchia). Brazilian Journal of Biology. 67(4): 721-726. https://doi.org/10.1590/S1519-698420070004 00019

Medina, A., Romero, M. and Narvarte, M. 2016. Radular morphology of Zidona dufresnei (Neogastropoda: Volutidae) and an analysis of its variability along the distributional range. Marine Biology Research. 2016;12: 211220. doi:10.1080/17451000.2015.1131297

Nantarat, N., Wade, C.M., Jeratthitikul, E., Sutcharit, C., and Panha, S. 2014. Molecular evidence for cryptic speciation in the Cyclophorus fulguratus (Pfeiffer, 1854) species complex (Caenogastropoda: Cyclophoridae) with description of new species. Huchon D, editor. PLoS One. 9(10): e109785. [accessed 2019 Jan 16]. Available from https://dx.plos.org/10.1371/journal.pone.0109785.https://doi.org/10.1371/ journal.pone. 0109785

Pfeiffer, L. 1856. Versuch einer anordnung der Heliceen nach natürlichen gruppen. Malakozool Blätter. 3: 112-185.

Pfeiffer, L.G.K. 1856. Novitates conchologicae. Series prima. Mollusca extramarina. Beschreiber und Abbildung, neuer oder kritischer Landund Süsswasser-Mollusken,. Cassel,: T. Fischer. editors Available from: https://www.biodiversitylibrary.org/item/41218.https://doi.org/10.5962 /bhl.title.10371

Prasankok, P., and Panha, S. 2011. Genetic structure of the common terrestrial pulmonate snail, Cryptozona siamensis (Pfeiffer, 1856), in Thailand. Biochemical Systematics and Ecology. 39(4): 449457.https://doi.org/10.1016/j.bse.2011.06.011

Rohlf, F.J. 2010. Tpsdig Version 2.16. New York: Department of Ecology and Evolution, State University of New York at Stony Brook.

Rohlf, F.J. 2012. Tpsutil Version 1.49. New York: Department of Ecology and Evolution, State University of New York at Stony Brook. 
Schilthuizen, M., Liew, T-S., Elahan, B.B., and Lackman-Ancrenaz, I. 2005. Effects of karst forest degradation on pulmonate and prosobranch land snail communities in Sabah, Malaysian Borneo. Conservation Biology. 19(3):949-954. https://doi.org/10.1111/j.1523-1739.2005.00209.x

Seed, J. M. 2015. Comparative radular morphology in some intertidal gastropods along Hormozgan province, Iran. Journal of Aquaculture Research \& Development. 6: 322. https://doi.org/10.4172/21559546.1000322

Sripalwit, P., Wongsawad, C., Wongsawad, P., and Anuntalabhochai, S. 2007. High annealing temperature-random amplified polymorphic DNA (HAT-RAPD) analysis of three paramphistome flukes from Thailand. Experimental Parasitology. 115(1): 98-102. https://doi.org/10.1016/j.exppara.2006.05.005

Sutcharit, C. 2018. Land snails the invaluable bio-resources for the Kingdom of Thailand. Bankok, Thailand: Thailand Science Research and Innovation (TSRI).

Swofford, D.L. 2003. PAUP*. Phylogenetic Analysis Using Parsimony (* and Other Methods). Version 4. Massachusetts: Sinauer Associates, Sunderland.

Thompson, J.D., Higgins, D.G., and Gibson, T.J. 1994. CLUSTAL W: improving the sensitivity of progressive multiple sequence alignment through sequence weighting, position-specific gap penalties and weight matrix choice. Nucleic Acids Research. 22(22): 4673-4680. http://www.ncbi.nlm.nih. https://doi.org/10.1093/nar/22.22.4673

Tuimala, J. 2004. A primer to phylogenetic analysis using Phylip package.

Vergara, D, Fuentes, J.A., Stoy, K.S., and Lively, C.M. 2017. Evaluating shell variation across different populations of a freshwater snail. Journal Molluscan Research. 37(2): 120-132. https://doi.org/10.1080/13235818. 2016.1253446

Vitta, A., Polsut, W., Fukruksa, C., Yimthin, T., Thanwisai, A., and Dekumyoy, P. 2016. Levels of infection with the lungworm Angiostrongylus cantonensis in terrestrial snails from Thailand, with Cryptozona siamensis as a new intermediate host. Journal of Helminthology. 90(6): 737-741. https://doi.org/10.1017/S0022149X150 01042

Walsh, P., Metzger, D. and Higuchi, R. 1991. Chelex 100 as a medium for simple extraction of DNA for PCR-based typing from forensic material. BioTechniques. 10(4):506-513.

Wongsawad, C., and Wongsawad, P. 2010. Molecular markers for identification of Stellantchasmus falcatus and a phylogenic study using the HATRAPD method. The Korean Journal of Parasitology. 48(4): 303-307. https://doi.org/10.3347/kjp.2010.48.4.303 


\section{SUPPLEMENTARY}

A

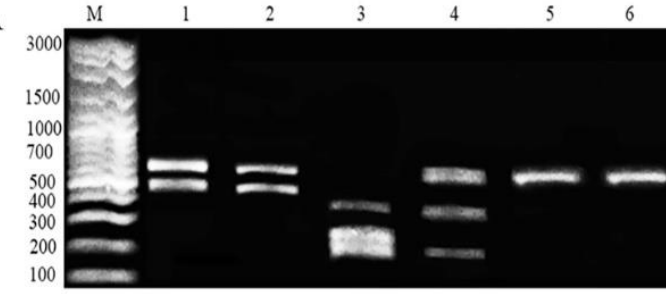

C

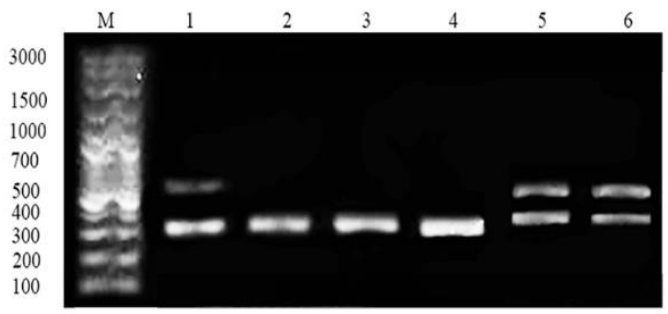

$\mathrm{E}$

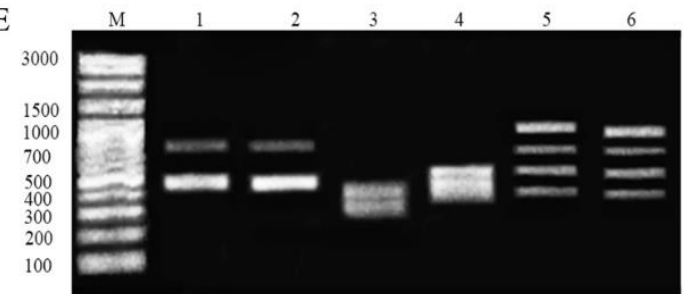

G

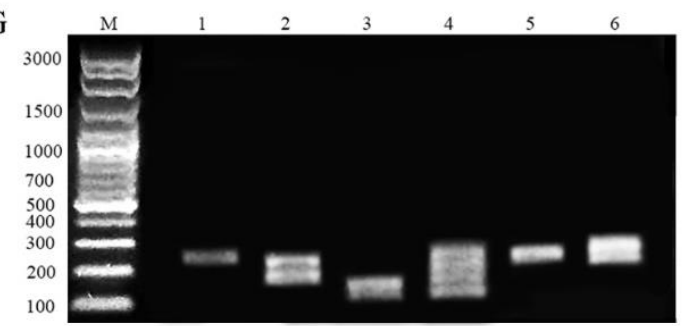

B
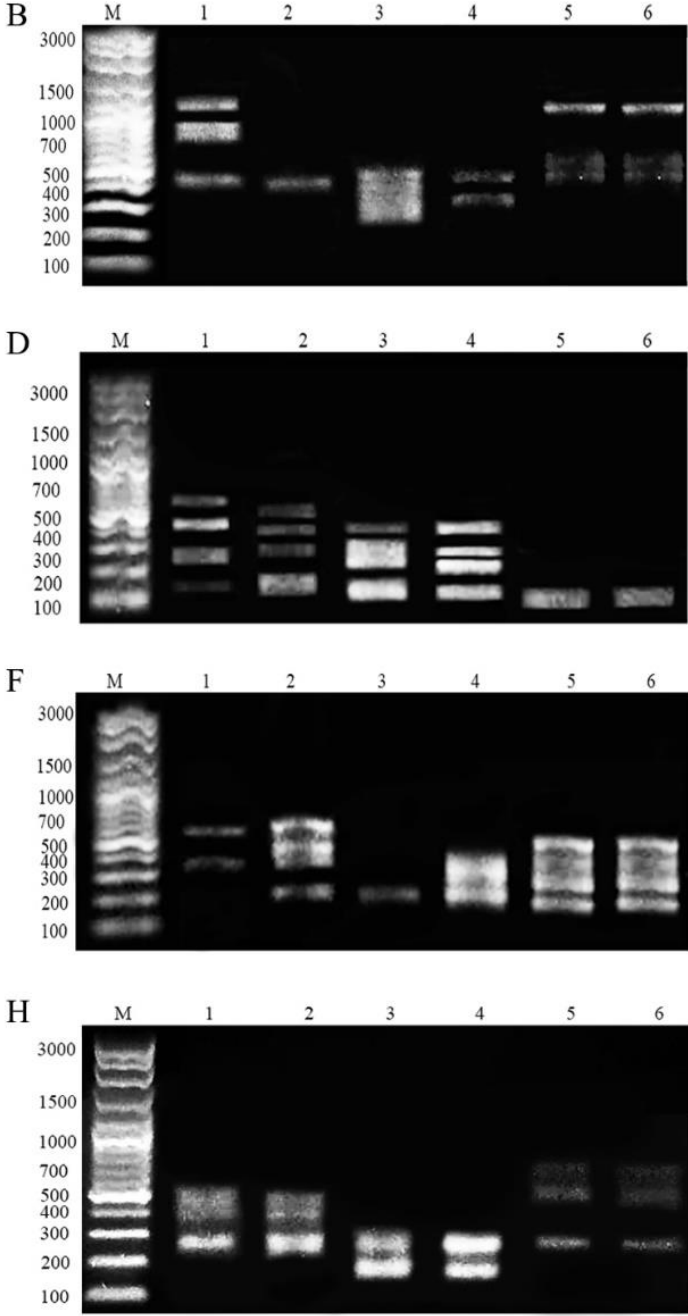

Supplementary 1. HAT-RAPD profiles of land snails generated with the OPA8 primer. (A) OPA02, (B) OPN02, (C) OPA03, (D) OPN03, (E) OPA04, (F) OPN04, (G) OPN06 and (H) OPA10. Lane M, 10-bp ladder; lanes 1 and 2, Cryptozona siamensis from limestone mountains in the Chiang Dao district and the Mae On district, respectively; lanes 3 and 4, C. siamensis from lowland habitats in the Mueang district and San Kamphaeng district, respectively; lanes 5 and 6, outgroup 